A. Maximilian Semmling, Anja Rösel, Dmitry V. Divine, Sebastian Gerland, Georges Stienne, Serge Reboul, Marcel Ludwig, Jens Wickert, Harald Schuh

\title{
Sea-ice concentration derived from GNSS reflection measurements in Fram Strait
}

Journal article | Accepted manuscript (Postprint)

This version is available at https://doi.org/10.14279/depositonce-11878

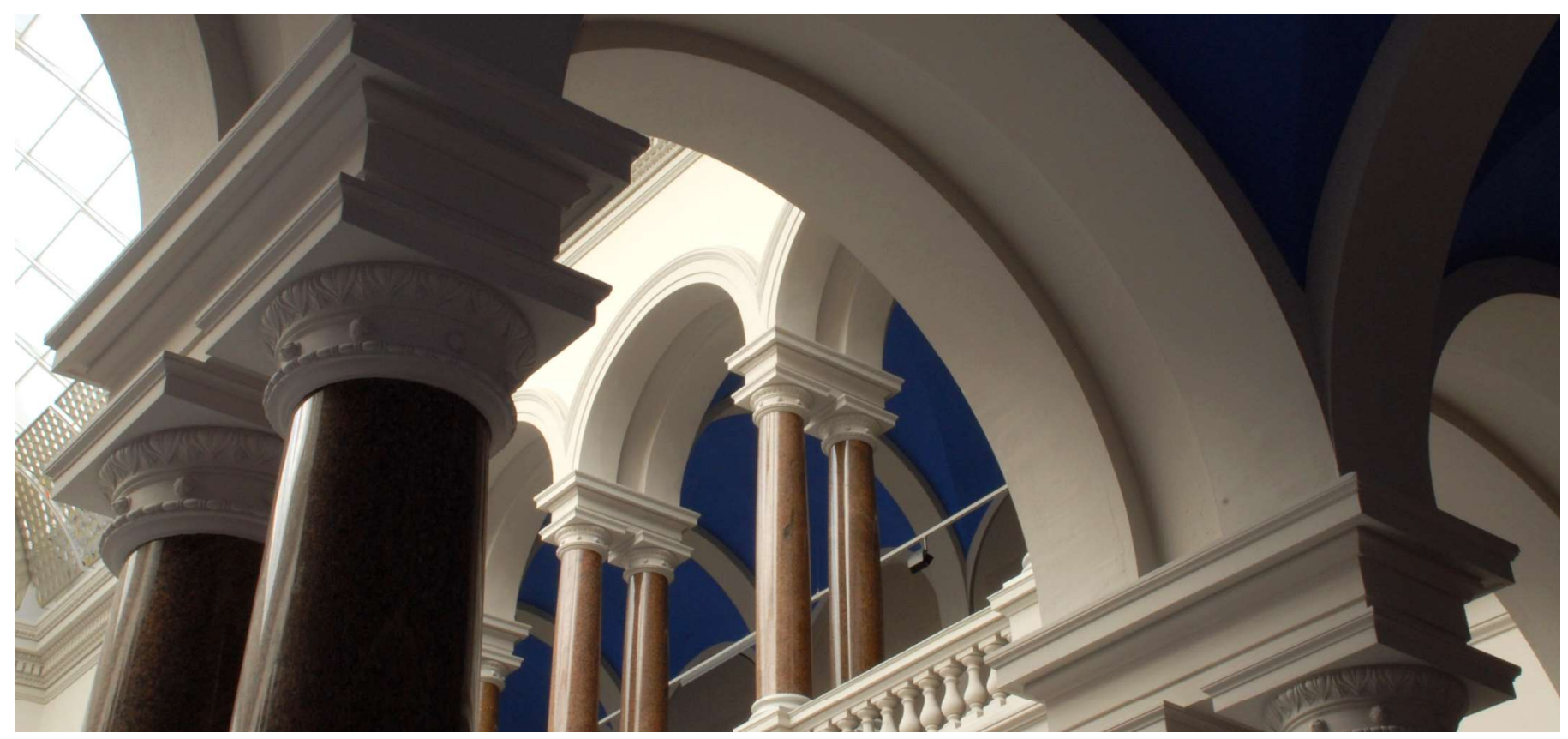

(c) 2019 IEEE. Personal use of this material is permitted. Permission from IEEE must be obtained for all other uses, in any current or future media, including reprinting/republishing this material for advertising or promotional purposes, creating new collective works, for resale or redistribution to servers or lists, or reuse of any copyrighted component of this work in other works.

Semmling, A. M., Rosel, A., Divine, D. V., Gerland, S., Stienne, G., Reboul, S., Ludwig, M., Wickert, J., \& Schuh, H. (2019). Sea-Ice Concentration Derived From GNSS Reflection Measurements in Fram Strait. IEEE Transactions on Geoscience and Remote Sensing, 57(12), 10350-10361.

https://doi.org/10.1109/tgrs.2019.2933911

\section{Terms of Use}

Copyright applies. A non-exclusive, non-transferable and limited right to use is granted. This document is intended solely for 
A. M. Semmling and M. Ludwig are with Helmholtz Centre Potsdam GFZ, Department of Geodesy, Potsdam, Germany, e-mail: maxsem@gfz-potsdam.de.

A. Rösel was with Norwegian Polar Institute, Fram Centre, Troms $\emptyset$, Norway and is currently with Deutsches Zentrum für Luft- und Raumfahrt DLR, Institut für Methodik der Fernerkundung, Oberpfaffenhofen, Germany.

D. Divine and S. Gerland are with Norwegian Polar Institute, Fram Centre, Tromsø, Norway.

G. Stienne and S. Reboul are with Laboratoire d'Informatique, Signal et Image de la Côte d'Opale, Calais, France.

J. Wickert and H. Schuh are with Helmholtz Centre Potsdam GFZ and with Technische Universität Berlin, Germany. 
Sea Ice Concentration, Reflectometry, Satellite Navigation Systems, Radar Applications.

\section{INTRODUCTION}

The ocean coverage with sea ice is an important parameter in the global radiation budget. The knowledge of extent and other sea ice properties is, furthermore, important for navigation in the Arctic. Sea ice observations are, therefore, of scientific and common interest. Fram Strait, situated between north-east Greenland and the Svalbard archipelago, is the only deep ocean link of the Arctic and the main pathway for fresh water export from the Arctic to the North Atlantic. Changes in the sea ice conditions, there, are a crucial indicator for the general development of sea ice in the Arctic and have been studied over long time periods already [1], [2].

Cruises of research vessels $(\mathrm{R} / \mathrm{V})$ are regularly conducted in this area that allow an in-situ sea ice characterization. A reflectometry experiment has been realized on the 2016 cruise of R/V Lance to explore reflected signals of a Global Navigation Satellite System (GNSS) for sea ice remote sensing. The motivation is to better understand the sea ice reflected signal and its polarization under different sea ice conditions. The incoming GNSS signal with a right-handed circular polarization (RHCP) is expected to change partly to left-handed circular polarization (LHCP) upon reflection. The ratio of polarizations depends on the permittivity of the reflecting medium, sea-ice or water in this case, and the signal's incidence angle. In general, it is expected that an improved understanding of signal polarization after sea ice reflection will advance reflectometry techniques to retrieve sea ice parameters, like ice concentration, thickness and salinity.

Several approaches towards GNSS sea ice remote sensing have been made already. Reflection measurements at LHCP have been reported for flights over sea ice in the Alaskan Arctic [3]. In this study the reflection power was used to estimate the sea ice permittivity and to resolve different ice types. A dual polarization setup has been used for coastal measurements at Disko Bay, Greenland, during sea ice evolution in arctic winter [4]. These studies indicate a loss of LHCP reflection power with increasing ice age and increasing sea ice concentration that could be attributed to the permittivity response of the signal. Other studies stated a roughness response for reflection over sea ice covered surfaces. The reflection power for either polarization increases going from a rough wind-driven open water surface to a smoother sea ice covered surface. Such a roughness response has been reported for setups at the Greenland and Swedish coast [5], [6] and for space-based setups [7], [8]. In general, it is difficult to separate roughness and permittivity 
response to retrieve permittivity related parameters like sea ice concentration. The difficulty has been avoided in a neural network approach that showed sensitivity to the sea ice concentration [9].

The objective of the here presented study is to examine polarimetric data for a calibration-free retrieval of sea ice concentration. Polarimetric means that signal components at LHCP and RHCP are included. The experiment extends the scope from previous findings on sea ice permittivity [3] to sea ice concentration taking into account dual-polarization reflection data. The ship-based setup focuses on the grazing angle reflection over the sea surface with elevation angles $<30^{\circ}$ at the specular point. The grazing geometry mitigates the roughness effect and is, therefore, suitable to study the permittivity effect of sea ice concentration.

The paper comprises six sections: I. the here-given introduction to the topic of GNSS reflectometry for sea ice monitoring, II. a description of the experiment including the study area and ship-based GNSS setup, III. a presentation of the method separating signal contributions and estimating first power then sea ice concentration, IV. the results with the retrieved power distributions and concentration estimates including a validation with ancillary data, V. a short discussion and finally VI. the conclusions.

\section{EXPERIMENT AND SETUP}

Reflectometry measurements were conducted during the Fram Strait cruise of the research vessel (R/V) Lance between 25 August and 13 September 2016 (day of year 238 to 257). The cruise, led by the Norwegian Polar Institute (NPI), is part of a program on long-term oceanographic measurements and sea ice monitoring in Fram Strait. In the given period Lance was sailing from Longyearbyen on Svalbard (A) westward across Fram Strait reaching the Eastern Greenland coast, passing the edge of land fast ice (B), Dijmphna Sund (C) and Iles-de-France (D) before sailing back eastward across Fram Strait to Longyearbyen (A), cf. the map in Fig. 1.

The cruise in late summer is launched after the season of summer melt. It is associated with the minimal sea ice extent in the Arctic. Though eastern Fram Strait is mostly ice-free this time of year, drift ice is typically encountered west of the prime meridian. The position of sea ice edge, the actual sea ice coverage, prevalent ice types and their spatial distribution may, however, vary substantially from year to year. Besides drift ice, an extensive area $\left(10^{3}-10^{4} \mathrm{~km}^{2}\right)$ of fast ice or sea ice locked in place between grounded icebergs tend to exist in a shallow area of Belgica Bank at $79^{\circ} \mathrm{N}$ off the northeast coast of Greenland. This area is known as Norske Øre 


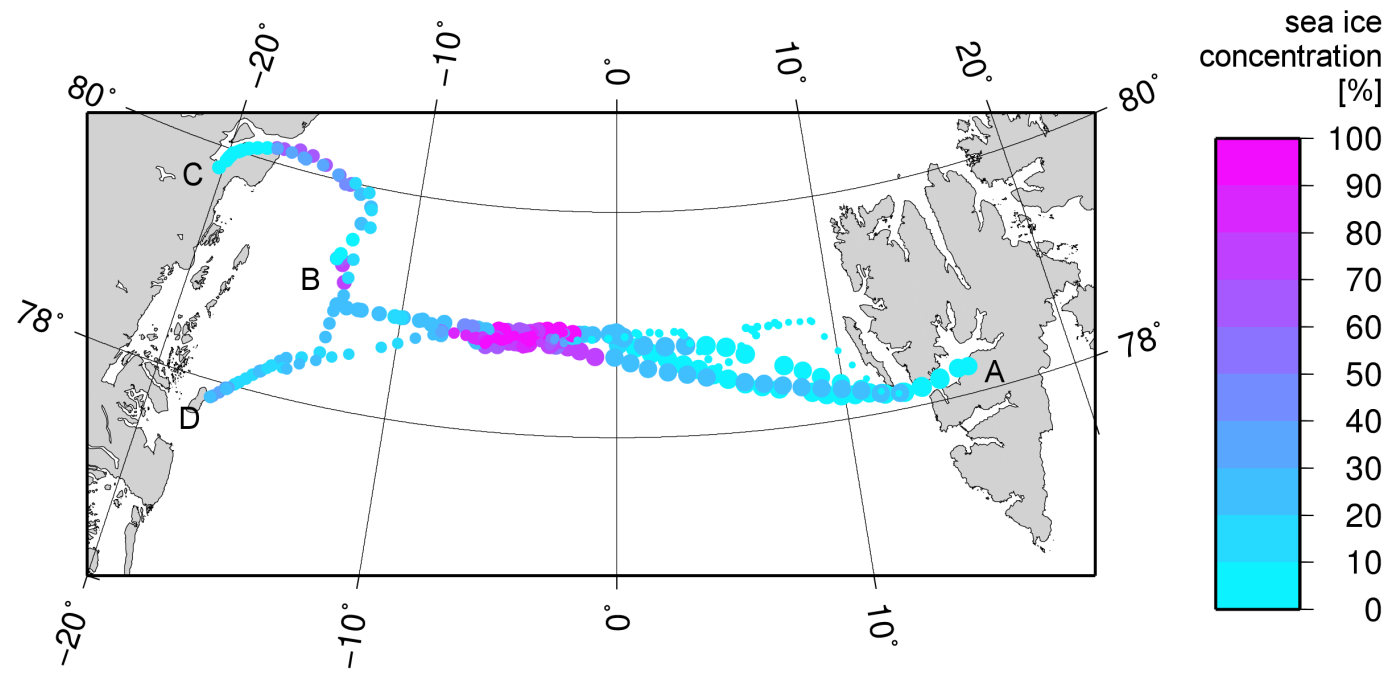

Fig. 1. Map indicating the ship's trajectory during the Fram Strait cruise: eight days from Longyearbyen (A), day 238, to the fast ice edge (B), day 246, five days along the Greenland coast sailing through Dijmphna Sund (C), day 248, further to Isles-de-France (D), day 250, and finally seven days back to Longyearbyen (A), day 257. The sea ice concentration from the ice watch is color-coded. The trajectory is resolved with $1 \mathrm{~h}$, dot size decreasing with time. Dates refer to day of year 2016. 


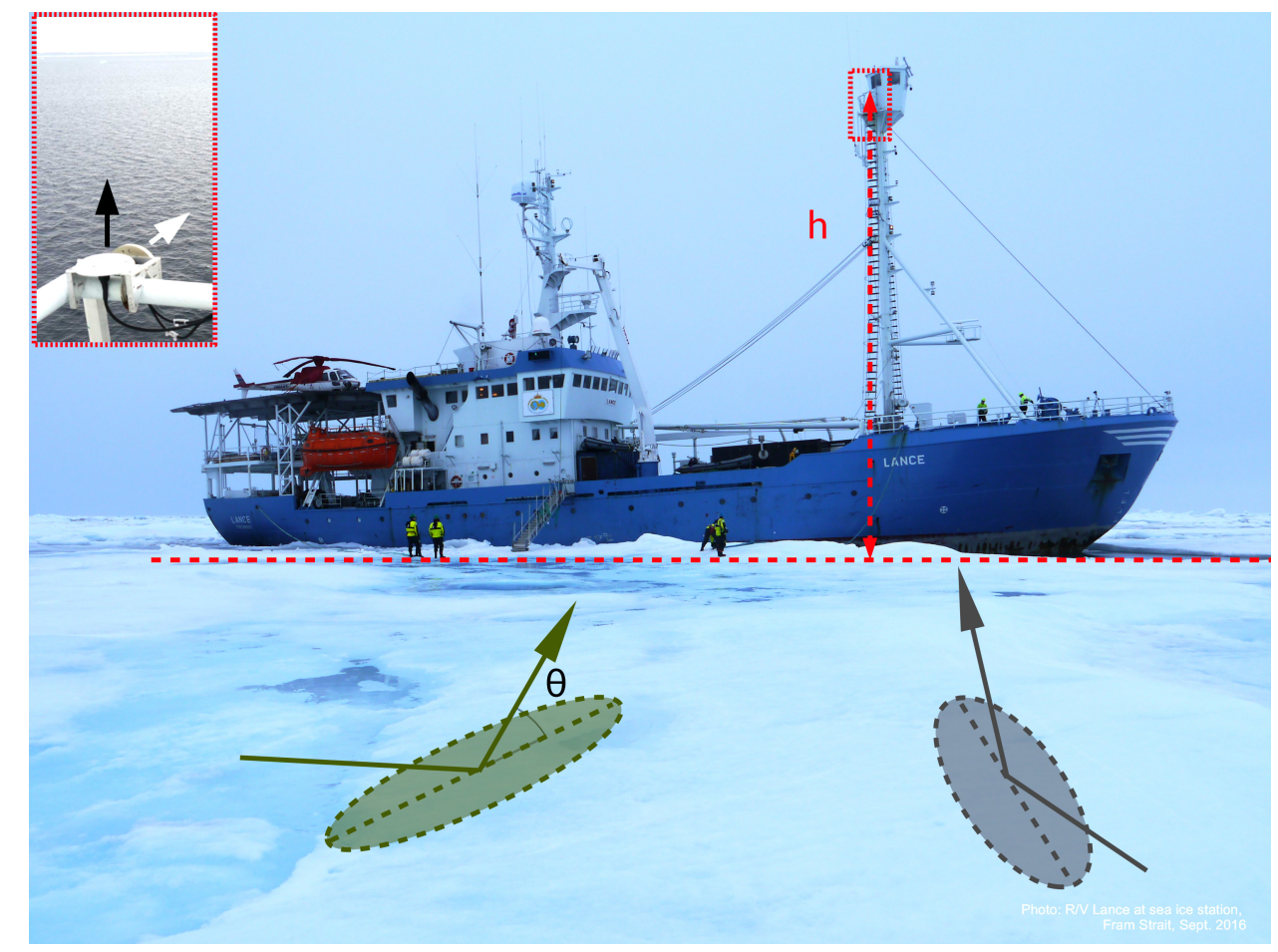
nest providing the three antenna links over cable lengths of $10 \mathrm{~m}$ each.

Fig. 2. Scheme of specular reflections over sea ice (equal elevation angles $\theta$ of the incident and reflected rays) received by the GNSS setup at crow's nest ( $h$ of $25.0 \mathrm{~m}$ above static water line). Simultaneous observation of reflection events is possible. The footprint ellipses around the specular point indicate the first Fresnel zone, with major (minor) axis $16 \mathrm{~m}$ (4 m) for a typical elevation angle of $16^{\circ}$. The main picture shows R/V Lance moored to a drifting ice floe during a sea ice station in central Fram Strait. The small picture (upper left) shows the up-looking and starboard-looking antennas with respective boresight directions (black and white arrows).

In the dynamic case when the ship navigates the antenna height, with respect to the water line, changes due to the ship's draft and attitude variations [15]. The receiver is located in the crow's 


\section{A. Separation of Compound Signal and Segmentation}

Samples of a compound signal with contributions (fringes) of direct and reflected signals have been studied already by [16] for a very similar setup. Referring to this previous work Doppler shifts are calculated to identify the contributions for separation. Reflection introduces a shift

$$
f(r)=\frac{1}{\lambda} \frac{d}{d t}\left(r-d_{0}\right)
$$

where $r$ is the path traveled by the reflected signal, $d_{0}$ is the direct signal path measured (tracked) at the master antenna and $\lambda$ denotes the wavelength of the signal carrier. In addition to the given Doppler shift of the reflected signal also a shift $f(d)$ of the direct signal is defined where $d$ refers to the path between slave antenna and the satellite. This effect is caused by the baseline between the master and the slave antenna that changes its orientation towards the transmitter. In case of a single antenna setup, without baseline, $d_{0}$ and $d$ are equal and the effect vanishes.

Segments with a length $T_{s}$ of 5 minutes are defined for signal separation on the two slave links. A 3rd-order polynomial fit and a Lomb-Scargle Periodogram (LSP) are applied to the segments in order to separate and quantify direct and sea surface reflected signal power, respectively. A similar approach has been described by [17] for a ground-based setup.

The approach can be applied to the dual-antenna ship setup within certain limits. A successful fit of the direct signal contribution requires that the corresponding period of variation is longer than twice the segment length $\left(T_{s}\right)$

$$
\begin{aligned}
T(d) & =\frac{1}{|f(d)|} \\
& >2 T_{s} .
\end{aligned}
$$

This requirement corresponds to a Doppler range that fulfills $|f(d)|<0.1 \mathrm{cpm}$ (cycles per minute). Ship's attitude changes, however, can increase the range of $f(d)$ beyond this limit, for example, during high sea states.

The detection of the sea surface reflection requires that direct and reflected signal's contribution are sufficiently separated in Doppler. It is the case if at least two complete periods of the reflected signal's fringes are within the segment length $\left(T_{s}\right)$ 


\begin{tabular}{cc|rrrrrr} 
PRN & GPS time & elev. $\left[^{\circ}\right]$ & roll range $\left[{ }^{\circ}\right]$ & yaw range $\left[{ }^{\circ}\right]$ & heave range $[\mathrm{m}]$ & $f(d)[\mathrm{cpm}]$ & $f(r)[\mathrm{cpm}]$ \\
\hline G10 & $2016 / 09 / 0311: 15$ & 2.2 to 4.2 & 2.6 & 26.2 & 0.09 & $0.02 \pm 0.07$ & $1.76 \pm 0.02$ \\
G23 & $2016 / 09 / 1309: 10$ & 4.1 to 2.3 & 20.8 & 18.5 & 3.66 & $0.02 \pm 0.22$ & $-1.68 \pm 11.70$ \\
\hline
\end{tabular}

TABLE I

LOW AND HIGH SEA STATE EXAMPLE EVENTS ON SEPTEMBER 3 AND 13, RESPECTIVELY. RANGES OF ROLL, YAW AND HEAVE ARE PEAK-TO-PEAK VALUES. DOPPLER SHIFTS ARE GIVEN BY MEAN VALUE AND THE CORRESPONDING STANDARD DEVIATION RANGE.

$$
\begin{aligned}
T(r) & =\frac{1}{|f(r)|} \\
& <T_{s} / 2 .
\end{aligned}
$$

The requirement corresponds to a Doppler range that fulfills $|f(r)|>0.4 \mathrm{cpm}$. This means that fringes of the reflected signal at a lower frequency cannot be detected. The important parameter of $f(r)$ is the antenna height with respect to the reflecting surface, cf. [16], which is $25.0 \mathrm{~m}$ in the static case.

Doppler shifts and relevant attitude changes, including heave (vertical ship motion), are given in Tab. I for two example segments at low and high sea states.

The high sea state segment is distinguished from the low sea state by a significantly larger range of roll and heave. It causes significant shifts $|f(d)|$ that exceed the limit of $0.1 \mathrm{cpm}$. Shifts $|f(r)|$ are, in general, sufficiently above the $0.4 \mathrm{cpm}$ limit indicating that separation of direct and reflected signals' contribution should be possible. In case of high sea state, however, a large spread of $f(r)$ occurs. The value $T_{s}$ of 5 minutes, considered here, can be modified keeping in mind the limits given by eq. (2), (3) and Tab. I.

\section{B. Coherent Power Estimation}

Power estimates result from a processing of the receiver output in the above defined segments. The output consists of $I$ (in-phase) and $Q$ (quadrature) amplitudes for the receiver's master and slave links with a $10 \mathrm{~Hz}$ sampling assumed, here. A common concept of signal demodulation to $I, Q$ amplitudes for a master/slave configuration is described by [18]. It also applies to the GORS receiver and can be extended to a compound signal. The receiver output with its direct and reflected contributions then reads 


$$
I_{c}+\mathrm{i} Q_{c}=\left(I_{d}+\mathrm{i} Q_{d}\right)+\left(I_{r}+\mathrm{i} Q_{r}\right)
$$

with respective subscripts $d$ and $r$. A 3rd-order polynomial fit is applied to retrieve $I_{d}, Q_{d}$. The output $I_{c}, Q_{c}$ and fitting retrievals $I_{d}, Q_{d}$ are plotted in Fig. 3, lower panel.
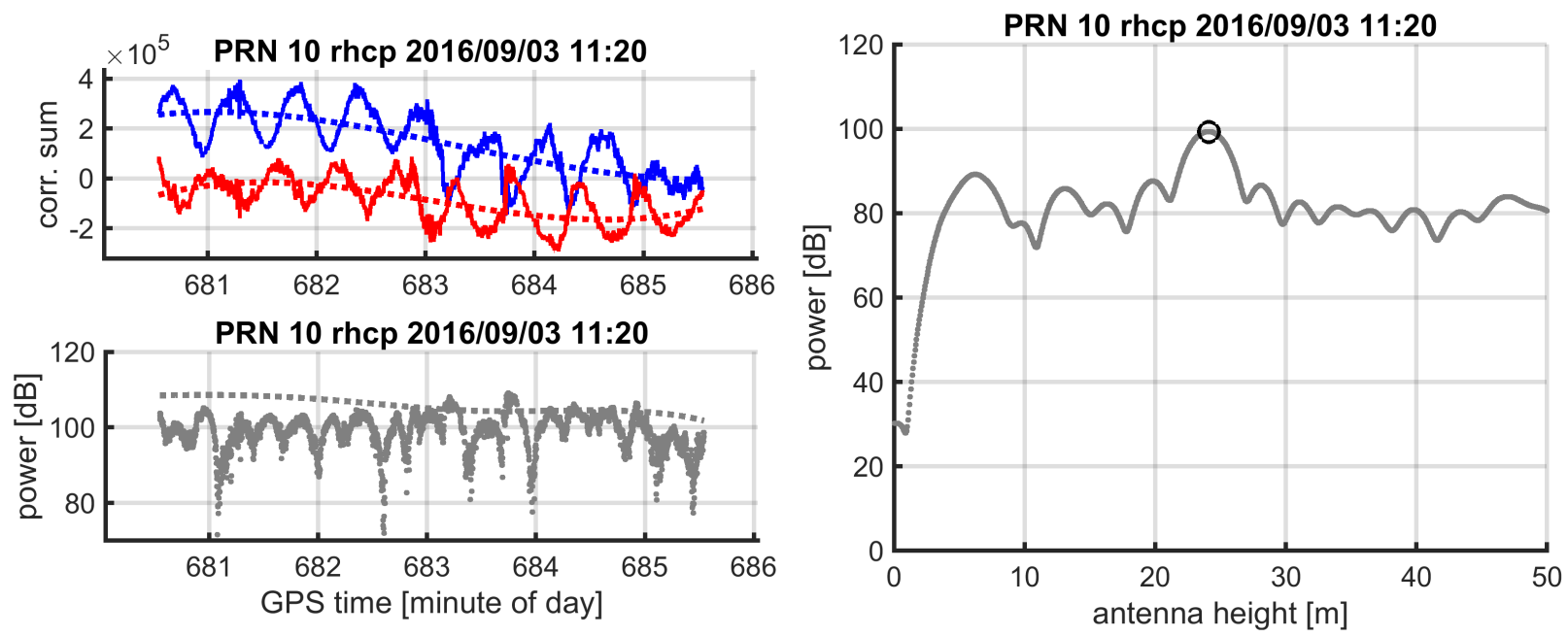

Fig. 3. Example of power estimation and multipath separation. Left panels: samples $I_{c}$ (blue) and $Q_{c}$ (red) with the respective fitting retrievals $I_{d}, Q_{d}$ (dashed lines), upper plot, and derived power $P_{r}$ (dots), $P_{d}$ (dashed line), lower plot. Right panel: power distribution $\tilde{P}(h)$ from the Lomb-Scargle Periodigram of the corresponding 5-minute segments. The peak lies close to the expected antenna height of $25.0 \mathrm{~m}$.

The direct signal power is calculated from the fitting results

$$
P_{d}=\left|I_{d}+\mathrm{i} Q_{d}\right|^{2}
$$

taking the squared magnitude of $I$ and $Q$. The mean value $\overline{P_{d}}$ and the standard deviation $\delta P_{d}$ are calculated for each segment. Amplitudes $I_{r}, Q_{r}$ are obtained from the differences $I_{c}-I_{d}$ and $Q_{c}-Q_{d}$ according to eq. (4). The reflection power $P_{r}$ and segment estimates $\overline{P_{r}}, \delta P_{r}$ are calculated using $I_{r}, Q_{r}$ analog to eq. (5). Variation of $P_{d}$ and $P_{r}$ within the example segment are shown in the lower left panel of Fig. 3. The variation within the segment weakens the precision. The reflected power that follows from eq. (4) can include any multipath and is not restricted to the sea surface. Dedicated power estimates of the specular sea surface reflection follow from the LSP. Therefore a variable transformation $t \rightarrow \sin [\theta(t)]$ is performed using the known time 
evolution of the satellite's elevation angle $\theta(t)$ as described by [17]. The LSP of transformed components $\tilde{I}_{r}, \tilde{Q}_{r}$ yields the power spectrum

$$
\tilde{P}_{r}(h)=\operatorname{LSP}\left[\tilde{I}_{r}\right]+\operatorname{LSP}\left[\tilde{Q}_{r}\right]
$$

which is resolved in a variable $h$ referring to the height between antenna and reflecting surface. It is assumed that the peak of $\tilde{P}_{r}$ corresponds to the specular sea surface reflection after removal of the direct signal contribution. Then power and height of the specular reflection are estimated by

$$
\left\{P_{s}, h_{s}\right\}=\max \left[P_{r}(h)\right]
$$

The LSP power spectrum with the respective peak is shown in the right panel of Fig. 3. In the following $P$ denotes signal power estimates after segment integration, using eq. (7) for the specularly reflected signal or using $\overline{P_{d}}$ for the direct signal. Additionally to the signal power estimates a noise power $P_{n}=\operatorname{var}\left[Q^{\text {master }}\right]$ is retrieved from the master antenna to quantify the signal tracking performance. It uses the variance, denoted var[.], over the $T_{s}$ segments of the quadrature component.

\section{Power Ratios and Estimation of Sea Ice Concentration}

Three different power estimates are considered from the two slave antenna links: the direct power on the right-handed link $P_{1}=P_{d}^{\text {right }}$, the reflected power on the right- and left-handed link $P_{2}=P_{s}^{\text {left }}, P_{3}=P_{s}^{\text {right }}$. Based on [19] adapted models for the power are found

$$
\begin{aligned}
& P_{1}=G_{d}^{\text {right }} P_{0} \\
& P_{2}=G_{s}^{\text {left }}\left|R^{\text {cross }}\right|^{2} W_{s}^{2} S_{2}^{2} P_{0} \\
& P_{3}=G_{s}^{\text {right }}\left|R^{\text {co }}\right|^{2} W_{s}{ }^{2} S_{3}^{2} P_{0}
\end{aligned}
$$

where $P_{0}$ is the incoming reference power at the receiver position, $G$ denotes the antenna gain, $R$ the Fresnel reflection coefficient, $W_{s}$ the power loss due to insufficient delay-Doppler tracking of the specularly reflected signal and $S$ the loss of the respective signal amplitude due to roughness of the reflecting surface. Dependencies on left-/right-handed and co-/cross-polar 
components are indicated. Indices $d, s$ refer to differences due to direct and specularly reflected signal paths. The incoming signal is assumed to be purely right-handed polarized.

The following method focuses on $R$ which contains the essential information on the effective sea surface permittivity $\epsilon_{\text {sea }}$. A single specular reflection off the sea surface is assumed. The coand cross-polar form of $R$ are written $R^{\text {co }}=(1 / 2)\left(R_{\|}+R_{\perp}\right)$ and $R^{\text {cross }}=(1 / 2)\left(R_{\|}-R_{\perp}\right)$ combining components with polarization parallel to the incidence plane $R_{\|}$and perpendicular to it $R_{\perp}$. In accordance with [20], assuming for a first order reflection at the air to sea interface, these components read

$$
\begin{aligned}
R_{\|} & =\frac{\epsilon_{\mathrm{sea}} \sin \theta-\sqrt{\epsilon_{\mathrm{air}} \epsilon_{\mathrm{sea}}-\left(\epsilon_{\mathrm{air}} \cos \theta\right)^{2}}}{\epsilon_{\mathrm{sea}} \sin \theta+\sqrt{\epsilon_{\mathrm{air}} \epsilon_{\mathrm{sea}}-\left(\epsilon_{\mathrm{air}} \cos \theta\right)^{2}}} \\
R_{\perp} & =\frac{\epsilon_{\mathrm{air}} \sin \theta-\sqrt{\epsilon_{\mathrm{air}} \epsilon_{\mathrm{sea}}-\left(\epsilon_{\mathrm{air}} \cos \theta\right)^{2}}}{\epsilon_{\mathrm{air}} \sin \theta+\sqrt{\epsilon_{\mathrm{air}} \epsilon_{\mathrm{sea}}-\left(\epsilon_{\mathrm{air}} \cos \theta\right)^{2}}} .
\end{aligned}
$$

depending on the respective permittivities $\epsilon$ and the elevation angle $\theta$.

A mixing of bulk medium permittivities is considered for the sea surface with a fractional area coverage according to sea ice concentration $C$, cf. the definition of mixing brightness temperatures for sea ice radiometry [21],

$$
\epsilon_{\text {sea }}(C)=C \epsilon_{\text {ice }}+(1-C) \epsilon_{\text {water }} .
$$

The following values of bulk permittivities in L-band are used: $\epsilon_{\text {air }}=1$ for the upper hemisphere, $\epsilon_{\text {water }}=76.4+48.5 \mathrm{i}$ for open water at $2^{\circ} \mathrm{C}$ and a salinity of $34 \mathrm{psu}$ [22]. The sea ice value $\epsilon_{\text {ice }}=3.31+0.11 \mathrm{i}$ is deduced from a brine volume calculation [23] and the permittivity retrieval described in [21] for $1.4 \mathrm{GHz}$ observations. The considered values of ice temperature and salinity are $-1{ }^{\circ} \mathrm{C}$ and $0.5 \mathrm{psu}$. They agree with the lower bound of ice salinity measured at the sea ice stations (dominating multiyear ice) and with previous observations in Fram Strait [1].

Six states of sea ice concentration are considered with $C$ between 0.0 and 1.0 in steps of 0.2 . They describe the sea ice concentration between open-water and complete sea ice cover with $20 \%$ resolution. Additionally six states of surface roughness are introduced based on values assumed for the standard deviation of the sea surface height $\sigma=\operatorname{std}\left[H_{\text {sea }}\right]$. These values go from 0 and $25 \mathrm{~cm}$ in steps of $5 \mathrm{~cm}$. According to the explicit form given by [19] these additional states alter the roughness loss 


$$
S(\sigma)=\exp \left(-\frac{1}{2} \frac{(2 \pi)^{2}}{\lambda^{2}} \sigma^{2} \sin ^{2} \theta\right) .
$$

This state-of-the-art roughness model is independent from the polarization. It has been considered to correct the power model, cf. $S_{2}$ and $S_{3}$ in eq. (8). It will be shown in the results that estimates $\sigma_{2}$ and $\sigma_{3}$ inverted from the respective power observations are different. Therefore, the indizes of $S$ are kept in the onward retrievals. The power estimates modelled in eq. (8) are combined to three power ratios (cross-, co- and cross-to-co-polar) minimizing the number of model unknowns

$$
\begin{aligned}
\tilde{P}_{2} / P_{1} & =\left|R^{\mathrm{cross}}(C)\right|^{2}\left|S_{2}(\sigma)\right|^{2} \\
\tilde{P}_{3} / P_{1} & =\left|R^{\mathrm{co}}(C)\right|^{2}\left|S_{3}(\sigma)\right|^{2} \\
P_{2} / P_{3} & =\frac{\left|R^{\mathrm{cross}}(C)\right|^{2}}{\left|R^{\mathrm{co}}(C)\right|^{2}}\left|S_{23}(\sigma)\right|^{2}
\end{aligned}
$$

For simplicity small letters $p$ with two respective indices will denote the ratios $p_{21}$ (cross), $p_{31}$ (co) and $p_{23}$ (cross-to-co). The tilde over $P_{2}$ and $P_{3}$ indicates that the power loss $W_{s}$ has been corrected. Furthermore gain factors $G$ cancel for the following reason: the gain pattern of the dual-polarization slave antenna is assumed to be equal for the two links $G^{\text {left }}=G^{\text {right }}$. Due to symmetry of $G$, with the antenna bore-sight pointing to the horizon, the gain $G_{d}$ of the direct signal (incidence angle $\beta$ ) and $G_{s}$ of the specularly reflected signal (incidence angle $-\beta$ ) are considered to be equal assuming the same azimuth of both signals. A generalized roughness effect with different values $S_{2}$ and $S_{3}$ is assumed. So the effect does not cancel in the cross-to-co polar ratio and a residual value $S_{23}$ is considered.

Under these assumptions the model is governed by the permittivity and the roughness effects with respective parameters $C$ and $\sigma$. A non-linear least-squares algorithm is applied to fit the models, eq. (12), to the respective power ratio observations. The squared error cost function

$$
\delta p^{2}(C, \sigma)=\frac{1}{m} \sum_{i=1}^{m}\left(p^{(i)}-h_{p}(C, \sigma)\right)^{2}
$$

is minimized for a discrete range of states $\{C, \sigma\}$ with $C$ out of $\{0,20,40,60,80,100\} \%$ and $\sigma$ out of $\{0,5,10,15,20,25\} \mathrm{cm}$. Power ratio observations are denoted $p^{(i)}$ with the index $i$ going up to the total number of observation $m$ considered for the estimation. The model hypothesis 


\begin{tabular}{l|rrrrrr} 
& $P_{d}^{\text {master }}$ & \multicolumn{1}{c}{$P_{d}^{\text {right }}$} & $P_{d}^{\text {left }}$ & $P_{r}^{\text {right }}$ & $P_{r}^{\text {left }}$ & \multicolumn{1}{c}{$P_{n}^{\text {master }}$} \\
\hline av. estimate & $98.2 \mathrm{~dB}$ & $99.2 \mathrm{~dB}$ & $84.5 \mathrm{~dB}$ & $89.5 \mathrm{~dB}$ & $88.8 \mathrm{~dB}$ & $62.3 \mathrm{~dB}$ \\
av. precision & $1.4 \mathrm{~dB}$ & $1.8 \mathrm{~dB}$ & $3.5 \mathrm{~dB}$ & $6.4 \mathrm{~dB}$ & $5.4 \mathrm{~dB}$ & - \\
\hline
\end{tabular}

TABLE II

RESULTS OF POWER ESTIMATION ON AVERAGE OVER THE WHOLE DATA SET

$h_{p}(C, \sigma)$ assumes the different ratios given in eq. (12). The number $m$ varies dependent on the recorded events within a $3 \mathrm{~h}$ integration period. For each period 36 (6 times 6) cost functions are calculated to cover the $C$ and $\sigma$ states.

Summarizing the method three data levels can be distinguished: the $I, Q$ amplitudes with $0.1 \mathrm{~s}$ resolution (level 0), power ratios $p$ derived from each segment after 5 minutes integration (level 1) and estimates $C$ after $3 \mathrm{~h}$ integration (level 2). All reflection events within $3 \mathrm{~h}$ of integration contribute to one estimate of $C$. The estimate footprint for $C$ covers, therefore, the whole swath around the ship over $3 \mathrm{~h}$ that means between $600 \mathrm{~m}$, when the ship is on station, and about $60 \mathrm{~km}$, when the ship goes straight at cruising speed in one direction. A global roughness estimate $\sigma$ is determined (level 2) that integrates over the entire days of the data set.

\section{RESUlts}

The results are sorted to the data levels. First the power ratio estimates (level 1) and the corresponding precision are shown. The ratios' distribution over the given elevation range and the agreement with the model prediction are regarded. In the second part estimates $\{C, \sigma\}$ (level 2) are presented.

\section{A. Estimated Power Ratios}

Estimation is based on 23065 segments (1922 hours) of GPS L1 data covering the 20 days of the cruise. Power values are estimated for each segment. Tab. II gives the average value and the corresponding average precision.

On average the relevant signal power, right-handed direct and both reflected polarizations, are significantly above noise level, between 27 and $36 \mathrm{~dB}$. Also the value of the direct signal power at left-handed polarization in considerable above noise level indicating an uncertainty in the polarization setting that assumes a clean right-handed incoming signal. It is important to note that precision of reflected power estimates is considerably lower compared to direct power 
estimates. It has consequences for further estimation as will be shown later. An important feature occurs for the distribution of noise power. A relation of noise power estimates to the ship's heave magnitude is shown in Fig. 4.

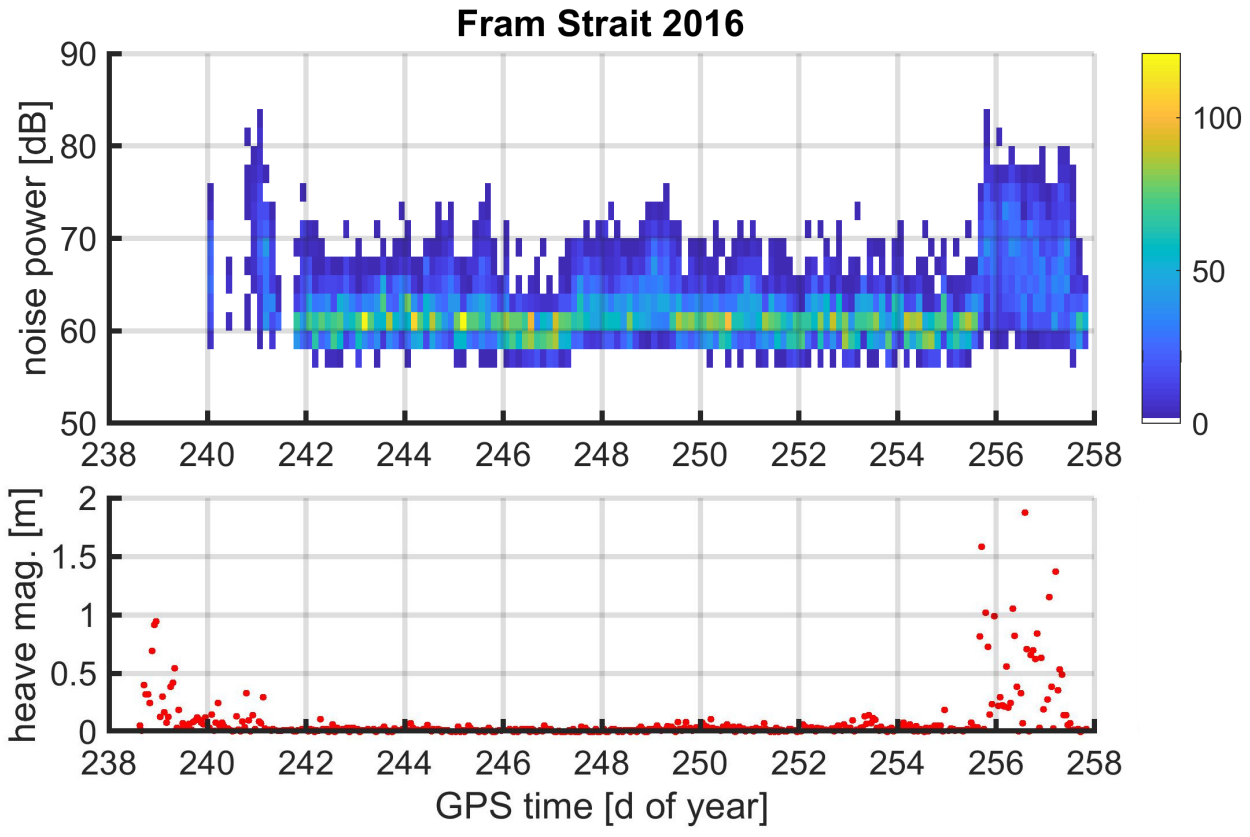

Fig. 4. Upper panel: noise power estimates over time of the cruise, the number of estimates is color-coded. Lower panel: magnitude of ship's heave.

Measurement noise increases during high sea states when the heave range reaches one meter and more. The performance of direct signal tracking (master antenna) decreases when the ship navigates through high sea states. For these states sea ice does not occur. A threshold $P_{n}<65 \mathrm{~dB}$ is set to exclude high sea states from $C$ estimation and thresholds $P_{j}>70 \mathrm{~dB}$ are set for all other observables, i.e. $j$ out of $\{1,2,3\}$ in order to guarantee a signal-to-noise ratio of at least $5 \mathrm{~dB}$.

The distribution of estimated power ratios $p_{23}, p_{21}$ and $p_{31}$ is plotted over the elevation range in the upper panels of Fig. 5. Respective model curves are added to relate the distribution to the pure permittivity effect. The distribution shows a large scatter with respect to the predicted effect. This scatter can be attributed to the low precision of power estimates on reflection links, see Tab. II. A deeper analysis is needed to examine the effects of changing permittivity or surface roughness. 

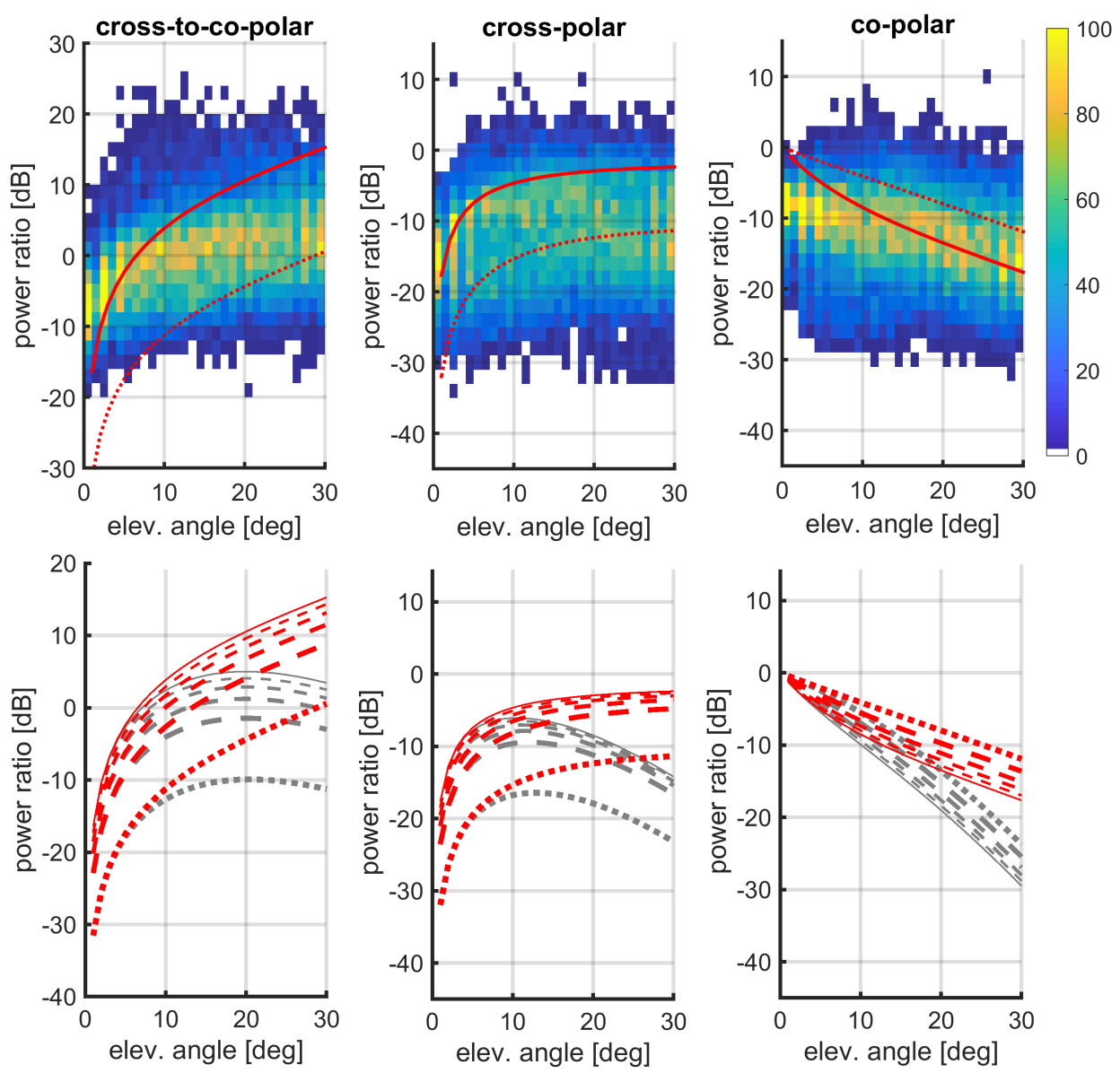

Fig. 5. Observed distribution and model prediction of power ratios $p_{21}$ (cross-polar), $p_{31}$ (co-polar) and $p_{23}$ (cross-to-co-polar) over elevation angle. Upper panels: distribution of observations color-coded between one per bin (dark blue) and more than 100 (light yellow); predicted boundaries of open water and complete ice cover (red solid and dotted lines). Lower panels: refined model prediction using permittivity-based model (red lines) from open water (solid), $C$ between 20 to $80 \%$ (dashed) to complete ice cover (dotted); model additionally refined with roughness effect $\sigma$ of $10 \mathrm{~cm}$ (gray lines).

The model is refined to account for the intermediate $C$ states and an additional roughness effect, see the respective curves in the lower panels of Fig. 5. Main features of the model prediction can be found in the distribution. In the given grazing angle elevation range the evolution is non-linear, an increase with elevation is detected for $p_{23}$ and $p_{21}$ whereas a decrease is stated for $p_{31}$. The roughness loss can turn $p_{23}$ and $p_{21}$ to decreasing above 10 to $20^{\circ}$ of elevation. An increase of $C$ is predicted to decrease the ratios $p_{23}$ and $p_{21}$ whereas the contrast is predicted for $p_{31}$. The distance between curves in Fig. 5 increase with $C$ value (the solid line is very close and the dotted line is significantly apart from its neighbour). This trend indicates that the power ratio can resolve higher $C$ values better than lower. 
The plots cannot yet resolve the variable sea ice concentration as they lack the time information. However, a peak of the observed distribution between the water line (red solid) and ice line (red dotted) is expected based on the assumption of mixing water and ice permittivity, cf. eq. (10). This feature occurs particularly for $p_{21}, p_{23}$. An overestimation $\left(p_{21}, p_{23}\right)$ by the pure permittivity model (red lines) occurs at highest elevation angles $25 . . .30^{\circ}$ where the distribution peak is at the ice line and below. An underestimation $\left(p_{21}, p_{23}\right)$ by the model occurs at lowest elevations $0 \ldots 5^{\circ}$, where the peak lies at the water line and above. The $p_{31}$ model shows a particular overestimation with the distribution peak mainly below the water line and seems to be least suitable for inversion of $C$. Including the roughness effect in the model of $p_{21}$ and $p_{23}$ can compensate overestimation.

In general the model fit is worst at lowest elevations. Neither the observed decrease of $p_{21}$ and $p_{23}$ nor the shift of reflected power to $p_{31}$ reach the amount predicted for elevation angles going towards zero.

It has to be taken into account that cross-polar and cross-to-co-polar power ratios can be affected by the individual automatic-gain-control (AGC) applied by the GORS receiver to each antenna link. The comparison of the AGC records during the cruise indicates differences of the signal gain below $10 \%$. Corresponding changes of $p_{21}$ and $p_{23}$ will thus be limited to $\pm 0.5 \mathrm{~dB}$ and are insignificant compared to the precision limits of power retrievals, cf. Tab. II.

\section{B. Estimated Sea Ice Concentration}

The data set of in total 20 days provides 161 estimates of $C$ with a temporal resolution of three hours and a single roughness estimate $\sigma$ integrating the whole data set. Fig. 6 shows scatter plots comparing $C$ estimates with corresponding ice watch results from the ship. Roughness estimates for the low sea state periods (low measurement noise) vary between 5 and $10 \mathrm{~cm}$, cf. Tab. III.

Good agreement in sea ice concentration occurs for the cross-polar $\left(C_{21}\right)$ and the cross-to-copolar $\left(C_{23}\right)$ estimates, correlation of 0.75 and 0.67 , respectively. Uncertainties of $C_{21}$ and $C_{23}$ are governed by the RMSE (root mean square error) with $25 \%$ and $31 \%$, respectively, cf. Tab. III. Particularly the high sea ice concentrations are underestimated by $C_{23}$, see the regression curve in Fig. 6 and the mean biases given in Tab. III. The co-polar $\left(C_{31}\right)$ estimates do not show an agreement, correlation of -0.28 . The response to sea ice does not confirm the expected permittivity effect in this case. High sea ice concentrations are particularly underestimated. Bias 


\begin{tabular}{c|rrrr} 
& roughness & correlation conc. & mean bias conc. & \multicolumn{2}{r}{ RMSE conc. } \\
ratio & $\sigma[\mathrm{cm}]$ & $\rho_{C}$ & $\overline{\Delta C}[\%]$ & $\sqrt{\overline{(\Delta C)^{2}}}[\%]$ \\
\hline cross-to-co & 10 & 0.67 & -19 & 31 \\
cross & 10 & 0.75 & 8 & 25 \\
co & 5 & -0.28 & -30 & 53 \\
\hline
\end{tabular}

TABLE III

ESTIMATION RESULTS FOR POWER RATIO AND SEA ICE CONCENTRATION. RESOLUTION OF $C$ BY POWER RATIOS $p$ GIVEN BY THE DERIVATIVE (TAKEN AT $15^{\circ}$ ELEVATION IN STEPS OF $20 \%$ CONCENTRATION), MEAN PRECISION OF POWER ESTIMATES $\overline{\delta p}$, ROUGHNESS ESTIMATES $\sigma$ AND PEARSON CORRELATION $\rho_{C}$ OF CONCENTRATION ESTIMATES WITH ICE WATCH RESULTS.
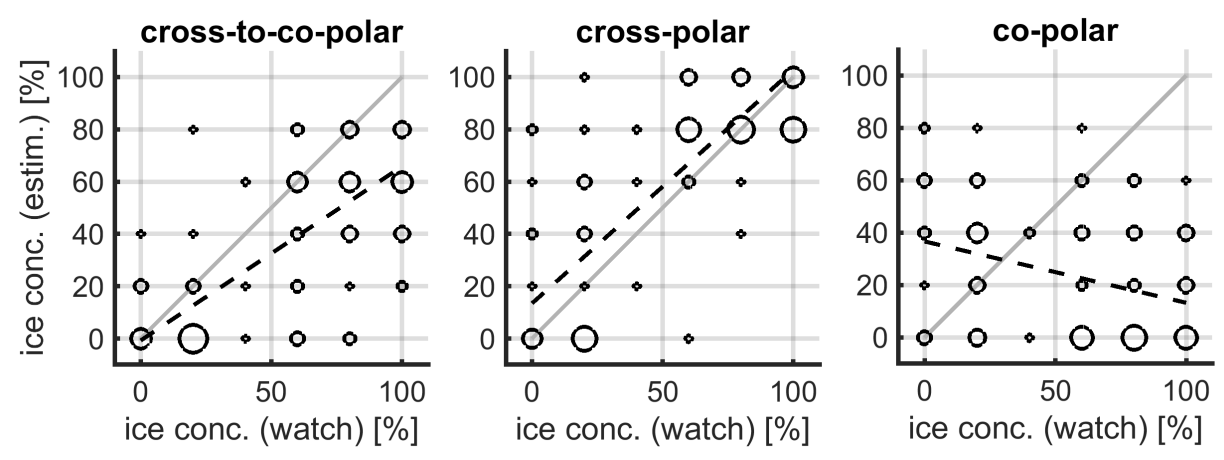

Fig. 6. Scatter plots for the different power ratios to compare sea ice concentration estimates and watch results, corresponding line fits (dashed) are added. In total 161 estimates are sorted to the bins with a $20 \%$ resolution. The marker size increases with the number of estimates per bin.

and RMSE for $C_{31}$ are significantly greater. The time-resolved results in Fig. 7 are restricted to estimates $C_{21}$ and $C_{23}$.

Results from the period of sea ice occurrence (days 239 to 255) in the left panel confirm the proposed concept to estimate the ice concentration. The comparison of reflection based estimates (blue, magenta) to results of the sea ice watch (black) show an agreement in main features: high concentration (mainly $>60 \%$ ) in the centre of Fram Strait (days 242 to 244), reduced concentration at the Greenland coast (days 244 to 251) with a significant anomaly (>60\%) at the fast ice edge (days 246 and 247) and again high concentration (>60\%) crossing the central part of Fram Strait on the way back (days 251 to 255). The rather large gap between estimates and watch results for the fast ice anomaly (days 246 and 247) relates to the starboard orientation of the slave antenna, the side facing the fast ice bulk when Lance was anchored there for two 


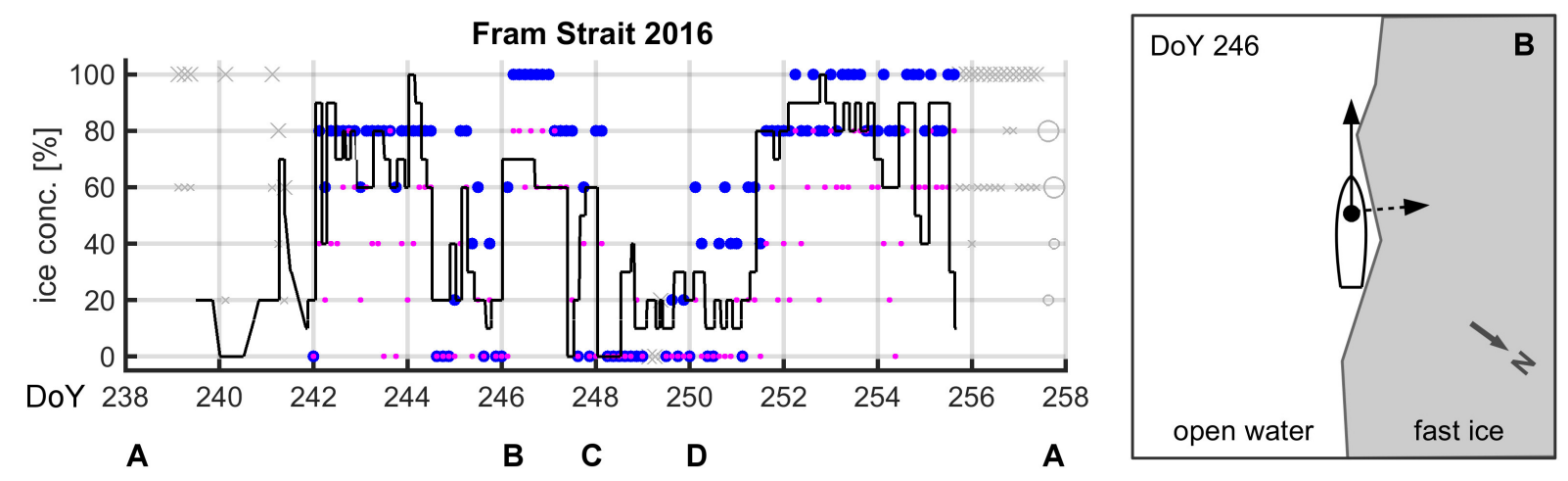

Fig. 7. Time resolved results of sea ice concentration estimation. Left panel: estimates using cross-polar (blue dots) and crossto-co-polar (small magenta dots) data; ambiguous periods of high sea states (crosses) and last day's land reflection (circles) are detected and masked (light gray); results of sea ice watch (black line) are added. Crucial points of the ship's trajectory are marked: start/end in Longyearbyen (A), two-days stay at the sea ice edge (B), stays in Dijmphna Sund (C) and at Isles-de-France (D). Right panel: ship's orientation relative to the fast ice during the mooring period (B) on day 246, schematic plot not to scale.

days, cf. scheme in right panel of Fig. 7. The ice watch reported $60 \%$ to $70 \%$ concentration taking into account the fast ice (starboard) and the wide open water area next to the fast ice edge (port side). The GNSS setup, looking starboard only, provided concentration of $80 \%$ to $100 \%$ dominated by the fast ice bulk.

In addition to the power thresholds introduced earlier, to mask high sea states and to achieve a minimum $5 \mathrm{~dB}$ signal-to-noise ratio, two more filters were applied for the results shown in Fig. 7. A threshold of at least 50 power estimates (segments) within the $3 \mathrm{~h}$ estimation interval is set to ensure the quality of the non-linear fit. A related lack of estimates is only found early in the data sets when still gaps in the continuous data recording occurred. The last six hours of the cruise, when the ship was in harbor, are excluded from sea ice estimation. This period of dominating land reflections was easily masked based on the ship's trajectory.

\section{Discussion}

In the following part the results are discussed pointing out the method's precision and resolution, reflection model and volume scatter as well as elevation dependence and roughness effect. 


\section{A. Method's Precision and Resolution}

Comparing the power residuals $\delta p$, as defined by the cost function in eq. (13), to the formal precision, set by the method, allows a better understanding of the results' uncertainty. The residuals and formal precision curves are shown in Fig. 8.
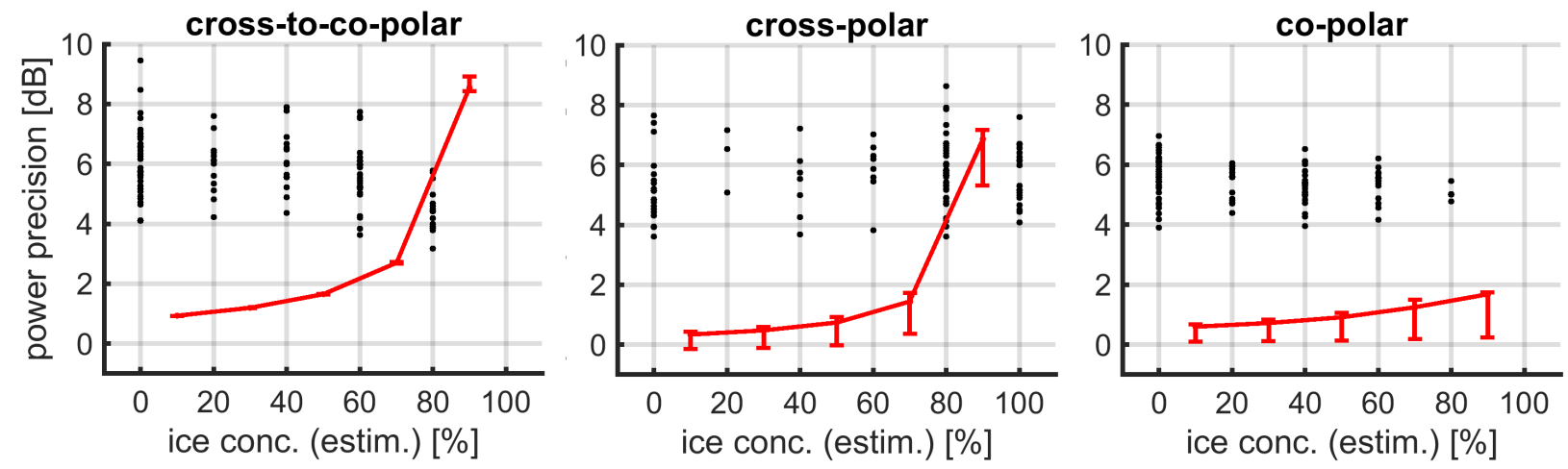

Fig. 8. Power residuals and formal precision. The residuals from the cost function (black dots) are compared to the precision curve set by method's formal resolution (red curve). The precision curve corresponds to the difference of power ratios between formally defined states of sea ice concentration, cf. distance of red curves in the lower panels of Fig. 5, values are plotted at intermediate points, e.g. $|p(40 \%)-p(20 \%)|$ at $30 \%$. The red error bars indicate the variability of precision over the considered elevation range, 5 to $30^{\circ}$.

The formal precision curve is calculated from $|\partial p / \partial C| \delta C$ where $\partial p / \partial C$ is the partial derivative of the ratio model given in eq. (12) and $\delta C$ is the method's resolution which is set to $20 \%$. For a sufficient resolution of states $C$ the residuals do not exceed the formal precision curve. With the given data it only holds for $p_{23}, p_{21}$ at highest concentrations. The uncertainty related to power precision increases towards low $C$ states. An improved precision of power estimates would probably reduce the residuals and improve the results of $C$ estimation. The performance on the reflection link, of $5.4 \mathrm{~dB}$ and above, is weak comparing it to the direct link, $1.8 \mathrm{~dB}$ and below, cf. Tab. II. A possible reason of the weak performance is additional multipath that affects the reflected link stronger than the direct link, see residual oscillations in the time domain that increase the variability of $P_{r}$, cf. lower left panel of Fig. 3.

The method's temporal resolution is an important point for further discussion. The segment integration time $T_{s}$ for power estimation, here set to 5 minutes, has a lower limit at about 1.5 minutes for the presented setup. Shorter segments will not reliably resolve fringes of the reflected signal. Longer values $T_{s}$ are only meaningful as long as power does not change during 

first-year and multiyear ice types were dominating with thickness usually greater than one meter as measured at the sea ice stations. Under these conditions volume scatter may occur, a significant second order reflection at the ice-to-water interface is not expected. The change of ice type distribution of power estimates within this period has to be sufficient for the non-linear fit. The $3 \mathrm{~h}$ value is chosen to meet the resolution of the ancillary ice watch observations. An additional roughness estimation cannot have the same temporal resolution without affecting the sea ice concentration results. Only a global roughness estimate is determined integrating over the total duration of measurements. A better resolution of sea ice concentration states (steps $<20 \%$ ) is currently not reasonable considering the RMSE values in Tab. III and the sensitivity to power precision, see Fig. 8.

\section{B. Reflection Model and Volume Scatter}

The comparison of results in Fig. 6 gives rise to discuss the reflection model. The results based on the co-polar ratio do not show the expected permittivity response to sea ice occurrence as it can be stated for the cross-polar results. A reason could be the volume scatter that may cause an additional loss when sea ice concentration increases. Such a loss is not included in the model yet. For the co-polar ratio the volume scatter loss would reverse the permittivity response to sea ice, which is actually a gain. For the cross-polar ratio, however, the loss goes along with the permittivity response, which is also a loss, cf. order of curves in Fig. 5. The permittivity response has also been studied for soil surface reflections based on a similar model. Although soil is a substantially different material than sea ice, there are similarities when looking at results from observations over soil [24] and the sea ice results presented here. A loss in the co-polar ratio occurs when soil permittivity decreases due to drying after precipitation. So in both studies the response of the co-polar ratio does not agree with the permittivity effect given by the Fresnel reflection coefficient. As a consequence the co-polar ratio appears less suitable and the cross-polar ratio gains more importance to study parameters that are related to permittivity, for example, ice concentration and ice type.

The model used here considers a single reflection at the air-to-sea interface. The sea, in this respect, is defined by states mixing sea ice and water according to eq. (10). In general, however, the L-band GNSS signals will partly penetrate into the ice. For thin ice a second order reflection at the ice-to-water interface may occur as it was reported by [25]. During the Fram Strait cruise 


\section{CONClusions}

A ship-based GNSS reflectometry experiment has been conducted aboard R/V Lance during its Fram Strait cruise in 2016. Analyzing the experiment this paper presents a method that provides power estimates using polarimetric data (left- and right-handed polarization) for an inversion of sea ice concentration. The sea ice concentration is resolved with a three-hour period along the ship's trajectory and the results are validated with ancillary ice watch data. Best agreement is achieved based on the cross-polar ratio of power estimates, which means left-handed reflected to 
right-handed direct signals. A 25\% RMSE persists in the results. An additional surface roughness effect has been taken into account with a $10 \mathrm{~cm}$ globally estimated standard deviation of the surface height. An advantage of using the cross-to-co-polar ratio instead, which means lefthanded reflected to right-handed reflected signals, is not detected. The co-polar ratio fails in the given concept. The necessity of a setup with left- and right-handed polarization links can be concluded. The roughness effect has to be considered to account for the respective loss even in the grazing angle range $\left(<30^{\circ}\right.$ elevation). A roughness correction that is independent from polarization, as proposed in [19], is not sufficient to describe the here presented observations on the left- and right-handed link. The considered roughness model fits better the left-handed than the right-handed signal. A detailed resolution of sea state conditions using, for example, the cross-polar ratio is left for future work.

Applying the here presented method to resolve sea ice concentration from a ship can enhance the options to validate other sensor data. The hardware efforts for the GNSS receiver setup are significantly reduced compared to microwave radiometers or SAR sensors. Furthermore a signal power calibration is not necessary in the given setup. The method is rather independent from ancillary data and robust under sea ice conditions, which means up to moderate sea states. Other observables, e.g. soil moisture, might be approached with this concept, also other receiver platforms are possible. Coherent reflection data over sea ice has also been reported from space-based records [25]. The resolution of sea ice concentration in such space-based records is anticipated for future work to foster sea ice applications and support the G-TERN mission concept [26].

\section{ACKNOWLEDGMENT}

We are grateful to Marius Bratrein, Markus Ramatschi and Thomas Gerber for support on setup and logistics. Crew and science team of the 2016 Fram Strait cruise are gratefully acknowledged. The longterm sea ice observations in Fram Strait are part of Norwegian Polar Institute's Fram Strait Arctic Outflow Observatory. The GNSS measurements were realized in the ArGID (Arctic GNSS Ice Detection) project funded by GFZ. The method development was supported by the French CPER MARCO programme (Marine Research at Côte d'Opale). The data, as output by the GORS receiver and used in this study, are public and can be provided via ftp on email request to maxsem@gfz-potsdam.de. 


\section{REFERENCES}

[1] W. B. Tucker, A. Gow, and W. F. Weeks, "Physical Properties of Summer Sea Ice in the Fram Strait," J. Geophys. Res., vol. 92, pp. 6787-6803, 1987.

[2] A. H. H. Renner, S. Gerland, C. Haas, G. Spreen, J. F. Beckers, M. Nicolaus, and H. Goodwin, "Evidence of Arctic sea ice thinning from direct observations," Geophys. Res. Lett., vol. 41, pp. 5029-5036, 2014.

[3] M. Belmonte Rivas, J. A. Maslanik, and P. Axelrad, "Bistatic Scattering of GPS Signals Off Arctic Sea Ice," IEEE Geosci. Remote Sens., vol. 48, no. 3, pp. 1548-1553, 2010.

[4] F. Fabra, E. Cardellach, A. Rius, S. Ribó, S. Oliveras, M. Belmonte, M. Semmling, and S. D’Addio, "Phase Altimetry with Dual Polarization GNSS-R over Sea Ice,” IEEE Geosci. Remote Sens., vol. 50, no. 6, pp. 2112-2121, 2011.

[5] A. M. Semmling, G. Beyerle, R. Stosius, G. Dick, J. Wickert, F. Fabra, E. Cardellach, S. Ribo, A. Rius, A. Helm, S. Yudanov, and S. d'Addio, "Detection of Arctic Ocean tides using interferometric GNSS-R signals," Geophys. Res. Lett., vol. 38, no. L04103, 2011.

[6] J. Strandberg, T. Hobiger, and R. Haas, "Coastal Sea Ice Detection Using Ground-Based GNSS-R," IEEE Geosci. Remote Sens. Lett., vol. 14, pp. 1552-1556, 2017.

[7] A. Alonso-Arroyo, V. U. Zavorotny, and A. Camps, "Sea Ice Detection Using U.K. TDS-1 GNSS-R Data," IEEE Geosci. Remote Sens., vol. 55, pp. 4989-5001, 2017.

[8] Y. Zhu, K. Yu, J. Zou, and J. Wickert, "Sea Ice Detection Based on Differential Delay-Doppler Maps from UK TechDemoSat-1,” Sensors, vol. 17, no. 1614, 2017.

[9] Q. Yan, W. Huang, and C. Moloney, "Neural Networks Based Sea Ice Detection and Concentration Retrieval From GNSS-R Delay-Doppler Maps,” IEEE App. Earth Obs. Remote Sens., vol. 10, pp. 3789-3798, 2017.

[10] N. E. Hughes, J. P. Wilkinson, and P. Wadhams, "Multi-satellite sensor analysis of fast-ice development in the Norske Øer Ice Barrier, northeast Greenland,” Annals of Glaciology, vol. 52, pp. 151-160, 2011.

[11] W. A. Sneed and G. S. Hamilton, "Recent changes in the norske фer ice barrier, coastal northeast greenland," Annals of Glaciology, vol. 57, pp. 47-55, 2016.

[12] ASSIST, "Arctic shipborne sea ice standardization tool," International Arctic Research Center, http://www.iarc.uaf.edu/icewatch, Tech. Rep., 2016.

[13] A. Helm, O. Montenbruck, J. Ashjaee, S. Yudanov, G. Beyerle, R. Stosius, and M. Rothacher, "GORS - a GNSS occultation, reflectometry and scatterometry space receiver," in ION GNSS 2007, pp. 2011-2021, 2007.

[14] L. Peraza, A. M. Semmling, C. Falck, O. Pavlova, S. Gerland, and J. Wickert, "Analysis of Grazing GNSS Reflections Observed at the Zeppelin Mountain Station, Spitsbergen,” Radio Science, vol. 52, pp. 1352-1362, 2017.

[15] O. Roggenbuck, J. Reinking, and A. Härting, "Oceanwide Precise Determination of Sea Surface Height from In-Situ Measurements on Cargo Ships," Marine Geodesy, vol. 37, pp. 77-96, 2014.

[16] A. M. Semmling, J. Wickert, S. Schön, R. Stosius, T. Gerber, M. Markgraf, M. Ge, and G. Beyerle, "A zeppelin experiment to study airborne altimetry using specular Global Navigation Satellite System reflections," Radio Science, vol. 48, pp. 427440, 2013.

[17] K. M. Larson, E. E. Small, E. D. Gutmann, A. L. Bilich, P. Axelrad, and J. J. Braun, "Using GPS multipath to measure soil moisture fluctuations: initial results," GPS Solutions, vol. 12, pp. 173-177, 2008.

[18] J.-C. Kucwaj, S. Reboul, G. Stienne, J.-B. Choquel, and M. Benjelloun, "Circular Regression Applied to GNSS-R Phase Altimetry," Remote Sens., vol. 9, no. 651, 2017.

[19] F. G. Nievinski and K. M. Larson, "Forward modeling of GPS multipath for near-surface reflectometry and positioning applications," GPS Solutions, vol. 18, pp. 309-322, 2014. 
[20] E. Cardellach, F. Fabra, A. Rius, S. Pettinato, and S. d'Addio, "Characterization of dry-snow sub-structure using GNSS reflected signals," Remote Sensing of Environment, vol. 124, pp. 122-134, 2012.

[21] L. Kaleschke, N. Maaß, C. Haas, S. Hendricks, G. Heygster, and R. T. Tonboe, "A sea-ice thickness retrieval model for 1.4 GHz radiometry and application to airborne measurements over low salinity sea-ice," The Cryosphere, vol. 4, pp. 583-592, 2010.

[22] A. U. Schmitt and L. Kaleschke, "A Consistent Combination of Brightness Temperatures from SMOS and SMAP over Polar Oceans for Sea Ice Applications," Remote Sens., vol. 10, no. 553, 2018.

[23] M. Leppäranta and T. Manninen, "The brine and gas contents of sea-ice with attention to low salinities and high temperatures," Technical Report 1988-2, Finnish Institute of Marine Research, 1988.

[24] A. Egido, M. Caparrini, G. Ruffini, S. Paloscia, E. Santi, L. Guerriero, N. Pierdicca, and N. Floury, "Global Navigation Satellite Systems Reflectometry as a Remote Sensing Tool for Agriculture," Remote Sens., vol. 4, pp. 2356-2372, 2012.

[25] W. Li, E. Cardellach, F. Fabra, A. Rius, S. Ribó, and M. Martín-Neira, "First Spaceborne Phase Altimetry over Sea Ice Using TechDemoSat-1 GNSS-R Signals," Geophys. Res. Lett., vol. 44, pp. 8369-8376, 2017.

[26] E. Cardellach, J. Wickert, and al., "GNSS Transpolar Earth Reflectometry exploriNg System (G-TERN): Mission Concept," IEEE Access, vol. 6, pp. 13980-14018, 2018.

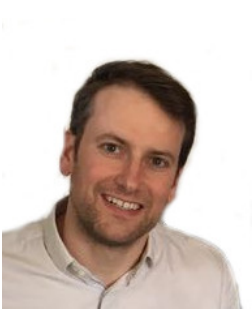

A. Maximilian Semmling graduated in physics from Leipzig University in 2007 and received the doctoral degree from Technische Universität Berlin in 2012. For his doctoral and post-doctoral studies he was with the German Research Centre for Geosciences (GFZ), Germany, the Institute for Space Studies of Catalonia (IEEC), Spain, and the University of the Littoral Opal Coast (ULCO), France. He is head of the GNSS reflectometry working group at GFZ. As principal investigator he is experienced in research projects in the field of GNSS remote sensing using airborne platforms (HALO research aircraft, Zeppelin airship), research vessels (Lance, Polarstern) and Arctic research stations (Disko Bay, Kongsfjorden). His research interest includes spacebased applications (GEROS-ISS concept, ADVANTAGE project and PRETTY mission). The main focus lies on altimetric and polarimetric methods in GNSS reflectometry for application in the Arctic.

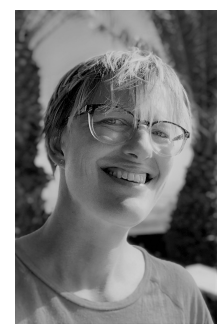

Anja Rösel received the Diploma degree from Ludwig-Maximilians University in Munich, Germany in 2002 and the Ph.D. degree from the University of Hamburg, Germany, in 2012. Her research interests include sea ice, snow mass balance from observations, and remote sensing of sea ice. She is currently emplyoyed at the Remote Sensing Technology Institute (IMF), German Aerospace Center (DLR), Oberpfaffenhofen, Germany, in the department EO Data Science as a research scientist. Before, she was a postdoctoral researcher at the Norwegian Polar Institute, Troms $\varnothing$, Norway. 


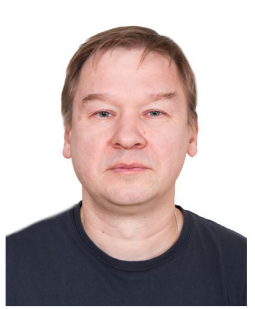

Dmitry V. Divine received the B.S. and M.S. degrees in physics and atmospheric physics from SaintPetersburg State University, Russia, in 1995 and 1998, respectively, and the Ph.D. degree in physical oceanography from the University of Bergen, Norway, in 2003. He was a Post-Doctoral Fellow with the Norwegian Polar Institute, Troms $\varnothing$, Norway, and the University of Troms $\varnothing$, The Arctic University of Norway, from 2003 to 2012. He is currently a Research Scientist in sea ice and paleoclimate with the Norwegian Polar Institute. His research interests in sea-ice remote sensing include the application of photogrammetry from low-altitude airborne imagery to study sea-ice processes at the broad range of spatial scales. Dr. Divine is a member of the European Geophysical Union.

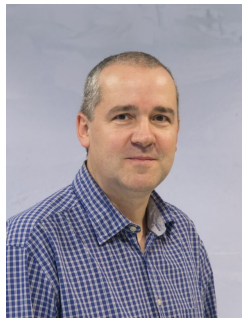

Sebastian Gerland received the Master's degree in geophysics (Dipl. Geophys.) from the Johann Wolfgang Goethe University, Frankfurt, Germany, in 1989, and the Ph.D. degree (Dr. rer. nat.) in marine sediment physics from the University of Bremen, Germany, in 1993. He has worked with Glaciology Groups at the Alfred Wegener Institute, Bremerhaven, Germany, at the University College of London, U.K., at the Norwegian Radiation Protection Authority, Akershus, Norway, and from 1997 to 2000 and since 2002 at the Norwegian Polar Institute, Troms, Norway, where he is a Senior Research Scientist for sea ice and climate, and since 2011 also a Leader of the section "Oceans and Sea Ice" in the Research Department of the institute. His research interests include sea ice mass and energy balance in the Arctic, with focus on the regions Fram Strait, Barents Sea, Svalbard, and Arctic Basin.

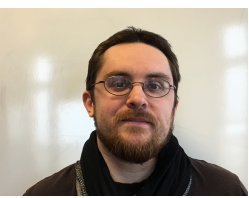

Georges Stienne received the Ph.D. degree from the University of the Littoral Opal Coast (ULCO), Calais, France, in 2013. After holding a Postdoctoral position at Purdue University, West Lafayette, IN, USA, he joined ULCO back as a lecturer in 2015. His research interests include the statistical processing of angular signals, with application to geolocation using the phase of GNSS signals, cycle slips estimation and earth observation using reflected GNSS signals.

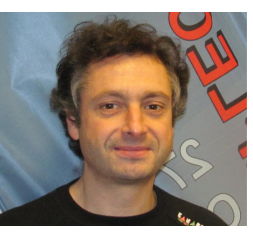

Serge Reboul received the M.Sc. degree in telecommunication and the Ph.D. degree in signal processing from Lille University of Science and Technology, Villeneuve-d'Ascq, France, in 1991 and 1995, respectively. He is currently working as a Professor with the University of the Littoral Opal Coast, Calais, France. He has been applying his research in the field of GNSS since 2002 and has been working on the reflectometry of GNSS signals since 2007. His research interests include the fields of signal processing and information fusion. 


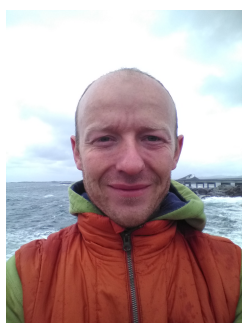

Marcel Ludwig is with the German Research Centre for Geosciences since 2000 working in mechanics and engineering. A focus of his work lies in dedicated solutions for GNSS reflectometry experiments on ground, ships and flight platforms. He is experienced in constructing drones in quadro- and hexacopter configuration for earth observation purposes. Moreover, a signifcant part of his work is committed to operational satellite laser ranging.

Jens Wickert received the graduate degree in physics from the Technische Universität Dresden, Germany, and the Ph.D. degree in geophysics/ meteorology from the Karl-Franzens-University Graz, Austria, in 1989 and 2002, respectively. He worked for several German geoscience institutes and holds a joint Professorship of GFZ and Technische Universität Berlin on GNSS Remote Sensing, Navigation and Positioning. Wickert is the GFZ Director for "The atmosphere in global change" research programme. He was Principal Investigator of the pioneering GPS Radio Occultation experiment aboard the German CHAMP satellite and is involved in numerous GNSS remote sensing research projects predominantly in leading positions. He is author/coauthor of around 250 ISI listed publications on GNSS Earth Observation.

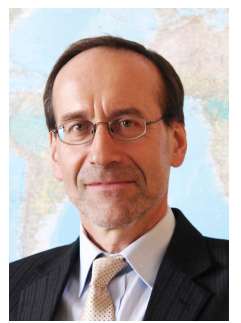

Harald Schuh is the elected President of the International Association of Geodesy (IAG), Past President of the IAU Commission 19 "Rotation of the Earth", and was Chair of the International VLBI Service for Geodesy and Astrometry (IVS) from 2007 to 2013. He has engaged in space geodetic research for more than 35 years with special focus on VLBI (Very Long Baseline Interferometry) and Earth rotation. Since 2012, he is Director of Department 1 "Geodesy" at the Helmholtz Centre Potsdam, GFZ German Research Centre for Geosciences and professor for "Satellite Geodesy" at Technische Universität Berlin. Harald Schuh is author or co-author of about 390 publications with the main subjects VLBI, GNSS, Earth rotation, geodynamics, geodetic reference frames, troposphere, and ionosphere. 